Proceedings

\title{
Seasonal Carbohydrate and Proline Allocation Patterns in Cyclamen graecum Link ${ }^{\dagger}$
}

\author{
John Pouris* and Sophia Rhizopoulou \\ Department of Botany, Faculty of Biology, National and Kapodistrian University of Athens, \\ Panepistimiopolis, 15784 Athens, Greece; jopouris@biol.uoa.gr \\ * Correspondence: jopouris@biol.uoa.gr; Tel.: +30-210-7274613 \\ + Presented at the 1st International Electronic Conference on Plant Science, 1-15 December 2020; Available \\ online: https://iecps2020.sciforum.net/.
}

Published: 3 December 2020

\begin{abstract}
This work is based on the study of the above- and below-ground tissues collected throughout a year, of the autumn-flowering geophyte Cyclamen graecum Link (Primulaceae). The geophytes are life forms that include underground storage organ reserves that support the initiation of leaf growth and flowering; their buds, resposible for their annual growth, remain protected below the soil surface on an underground perennial organ and their growing and flowering period alternates with a period of dormancy. The purpose of this study is to estimate the seasonal fluctuation of sugars, starch and proline that contribute to the adaptation of $C$. graecum to the Mediterranean ecosystem. A considerable amount of substances are allocated to leaves via transfer from root resources, photosynthates and senescing inflorescences. The total sugar content was determined using a modified phenol-sulphuric acid method. Quantitative determination of starch content was accomplished in sugar-free aliquots of dried tissues, which were solubilized in perchloric acid and the starch content was estimated using a modified anthrone method. Proline content was determined with acid-ninhydrin method. The above ground tissues of $C$. graecum that are exposed to ambient environmental conditions may exhibit seasonal responses to abiotic stresses. It seems likely that monthly fluctuations of proline accumulation, sugars and starch content obtained in the above- and below-ground tissues of $C$. graecum coincide with the distinct seasonality of the ecosystem. The highest sugar content, among the considered plant parts, was detected in the tubers, whereas the lowest in peduncles and petals in late autumn. Relatively elevated sugar content was detected in the leaves from December to April, probably associated with constraints of the vegetative growth of this species. Throughout the flowering period of $C$. graecum (September-December), similar trends of sugar content were detected between petals and peduncles. Starch is stored in tubers and leaves of $C$. graecum and the elevated values from March to April coincide with elevated photosynthetic rates. The accumulation of sugars and proline in petals from September to December may result to a reduction of their osmotic potential, which is expected to maintain their turgor and avoid the harmful effect of the cold period. Additionally, the pronounced proline accumulation in expanded leaves of C. graecum from November to April indicates the protective role of proline in tissues exposed to ambient environmental conditions.
\end{abstract}

Keywords: Cyclamen graecum; geophytes; hysteranthous species; mediterranean seasonality

\section{Introduction}

Life forms of the plants are important characteristics of their adaptation to abiotic environmental conditions; among them the geophytes are plants with an underground storage organ that supports their annual growth [1-3]. Cyclamen graecum Link, Linnaea 9(5): 573 (1835) is a perennial, tuberous geophyte, with an annual cycle where seasonal periods of vegetative growth alternate with seasonal cessation of the aboveground growth of this species. The name Cyclamen, which has been attributed to the genus, can be found in Theophrastus' writings (Historia Plantarum and De Causis Plantarum, 371-287 BC) [2,4]. Also, the name of the genus Cyclamen is considered to be derived from the Greek

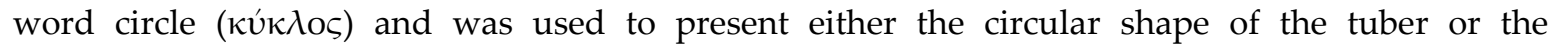


characteristic circular coiled fruiting stalk [5]. The leaves and the flowers of Cyclamen species emerge from particular tissues of the upper surface of the tuber; in most Cyclamen species as well as in Cyclamen graecum these tissues are concentrated in the center of the upper surface of the tuber [6].

The dark green, heart-shaped leaves of Cyclamen graecum are slightly angular with spots on the upper side and violet on the lower surface, i.e., variegated leaves. The violet color located at the bottom of the heart-shaped leaf is a result of the accumulation of a significant amount of anthocyanins and is a feature of the genus [7]. Anthocyanins have been shown to provide plant tissues with protection from a variety of abiotic and biotic adverse factors, such as dehydration and low temperatures, as well as herbivores or pathogens [8]. Another common leaf feature, among the different species of the genus Cyclamen, is that the leaves have a characteristic two-tone color, with parts of the leaf being light green, while others are dark green. This is due to both the chlorophyll content and the different structure of the pile midsole and affects both the density of the leaf and the penetration of sunlight [9].

Rough estimates show that among the various species of the genus Cyclamen the subterranean organ, the tuber, has the same form; a closer look, however, shows that the tuber differs in shape, size and the texture of its surface. In some species the surface of the tuber is smooth, while in others, including Cyclamen graecum, it progressively becomes rough and the roots are usually fibrous and branching. In Cyclamen graecum new large in diameter roots are developed between the fibrous roots. The role of these roots is not fully clarified. It is expected that they penetrate deeper into the stony substrates of the habitat of Cyclamen graecum [7].

The flower of Cyclamen graecum consists of five pink petals. Cyclamen graecum is hysteranthous geophyte, i.e., its flowering occurs before leaf emergence in September. The calyx which has the shape of a bell and the rim surrounds the stamens which are usually angular or toothed [10].

Species of the genus Cyclamen are distributed in parts of Europe, West Asia and North Africa. Specifically, Cyclamen graecum is growing in southern Greece, the Peloponnese, the Aegean islands as well as the southern coastal region of Turkey and northern Cyprus [10].

\section{Experiments}

The present study was carried out on tubers, leaves, peduncles, and petals collected from patches of Cyclamen graecum Link grown naturally on rocky ground in Greece $\left(37^{\circ} 57^{\prime} 58.1^{\prime \prime} \mathrm{N}\right.$ $23^{\circ} 47^{\prime} 16.1^{\prime \prime}$ E). Aboveground and belowground plant tissues were sampled from plants at monthly intervals throughout a year, i.e., from January (I) to December (XII). Monthly mean temperature and monthly precipitation, during the study period, were obtained from the meteorological enclosure, provided by the National Observatory of weather conditions in Greece. The climate of the study site is Mediterranean with a marked seasonality, typified by the alternation of a cold and wet period with a hot and dry period. During the study period, the mean air temperature of the cold (DecemberFebruary) and the hot (June-August) season was 11.2 and $27.6^{\circ} \mathrm{C}$, respectively (Table 1). Also, the average rainfall (Table 1) fluctuated, i.e., $111.1 \mathrm{~mm}$ in winter (XII-II), $27.4 \mathrm{~mm}$ in spring (III-V), 4.1 $\mathrm{mm}$ during summer (VI-VIII) and $43.3 \mathrm{~mm}$ in autumn (IX-XI).

Table 1. Mean monthly values of air temperature (T) and rainfall (R), from January (I) to December (XII).

\begin{tabular}{ccccccccccccc}
\hline Months & I & II & III & IV & V & VI & VII & VIII & IX & X & XI & XII \\
\hline $\mathrm{T}\left({ }^{\circ} \mathrm{C}\right)$ & 10.9 & 12.2 & 14.2 & 18.5 & 23.6 & 25.9 & 28.2 & 28.8 & 24.8 & 19.2 & 16.1 & 10.5 \\
\hline $\mathrm{R}(\mathrm{mm})$ & 89.6 & 153.4 & 42.3 & 25.5 & 14.3 & 8.0 & 4.3 & 0.0 & 0.0 & 22.4 & 107.6 & 90.2 \\
\hline
\end{tabular}




\subsection{Estimating Total Sugars and Starch Content}

Sugar content was estimated spectrophotometrically [11]. Total sugars were extracted from dried plant tissue (d.w.) in $80 \%$ ethanol $(v / v)$, and the tissue residue was used to determine the starch content. Grounded samples were placed in $10 \mathrm{~mL} 80 \%$ ethanol $(v / v)$, in a shaker, and the extracts were filtered using Whatman \# 2 filter paper. Sugar concentration was determined using a modified phenol-sulphuric acid method [12]. Quantitative determination of starch content was accomplished in sugar-free aliquots of dried tissues, which were solubilized in perchloric acid and the starch content was estimated using a modified anthrone method [13]. The values are expressed as $\mathrm{mg} \mathrm{g}^{-1}$ d.w.; D-glucose (Serva, Heidelberg, Germany) aqueous solutions were used for the standard curve.

\subsection{Estimating Proline}

The tissues' proline content was determined spectrophotometrically [14,15]. Dried samples were crushed into fine powder with liquid nitrogen and homogenized with aqueous sulphosalicylic acid $(20 \mathrm{~mL}, 3 \% \mathrm{w} / \mathrm{v})$, and the homogenate filtered through Whatman \# 2 filter paper. A total of $2 \mathrm{~mL}$ of the filtrate reacted with acid-ninhydrin solution $(2 \mathrm{~mL})$ and glacial acetic acid $(2 \mathrm{~mL})$ in triplicate test tubes, which were heated at $100{ }^{\circ} \mathrm{C}$ for $1 \mathrm{~h}$ in a water bath and the reaction terminated in an ice bath. After cooling, the reaction mixture was extracted with $4 \mathrm{~mL}$ toluene, and homogenized in a vortex. The chromophore containing the toluene was aspirated from the aqueous phase, and the absorbance was measured at $\lambda=520 \mathrm{~nm}$, using toluene as a blank sample. The proline content is expressed as $\mu \mathrm{mol} \mathrm{g}{ }^{-1}$ d.w.; L-proline (Serva, Heidelberg, Germany) solutions were used for the standard curve.

\section{Results}

\subsection{Sugars}

The highest sugar content, among the considered plant parts, was detected in the tubers (Figure 1), whereas the lowest in peduncles in November and in petals in November and December. Relatively elevated sugar content was detected in the leaves from December to April, probably associated with constraints of the vegetative growth of this species. Similar trends of sugar content were detected between the petals and the peduncles, throughout the flowering period (SeptemberDecember). Significant differences were found among seasonal values of leaf and tuber sugar content (not shown here).

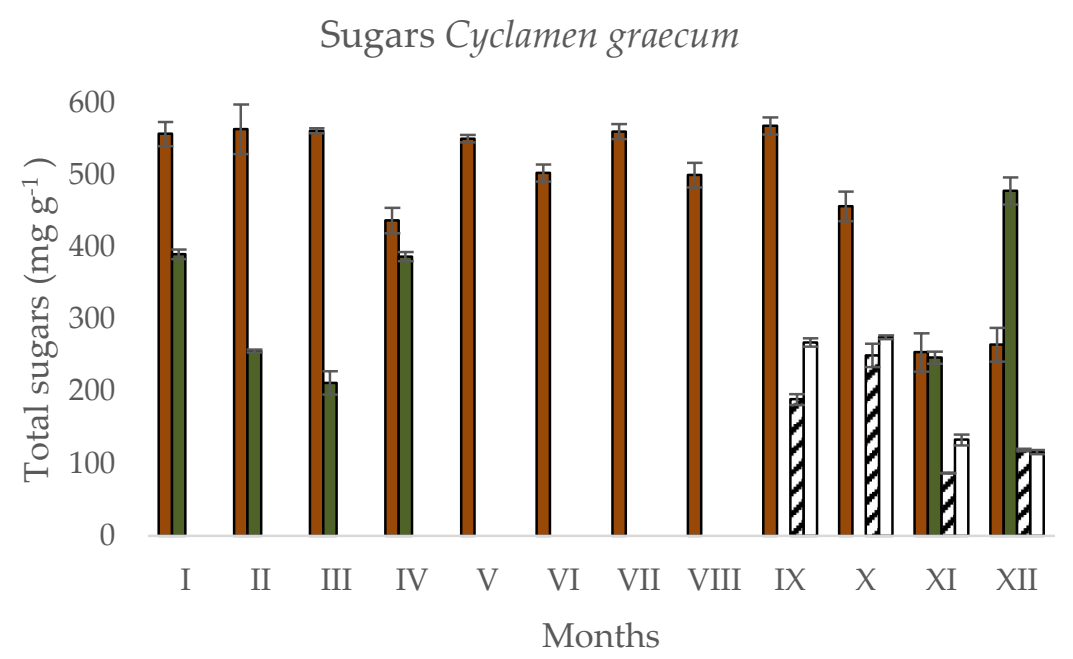

Figure 1. Sugar content in tubers (brown bars), leaves (green bars), peduncles (dashed bars), and petals (white bars) of Cyclamen graecum, from January (I) to December (XII). Each column denotes means of five replicates \pm Standard Error. Standard Errors smaller than the line thickness of the columns are not shown. 


\subsection{Starch}

The highest starch content in the tubers of C. graecum was observed in March and April when the climatic conditions were favorable for photosynthesis in the Mediterranean ecosystems, thereafter, starch content declined (Figure 2); intermediate values of starch content were detected in tubers from January to February and the lowest value of starch content was observed during summer. The starch content in leaves was high during winter. The values of starch content in peduncles were elevated between November and December, while the starch of peduncles was substantially lower from September to October. The relatively low values of starch content in petals were not significantly different.

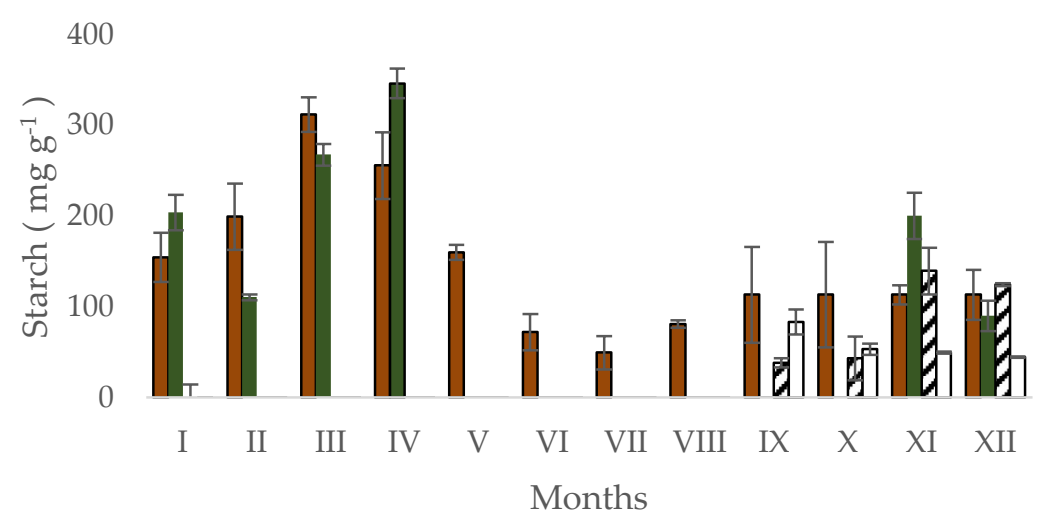

Figure 2. Starch content in tubers (brown bars), leaves (green bars), peduncles (dashed bars) and petals (white bars) of Cyclamen graecum, from January (I) to December (XII). Each column denotes means of five replicates \pm Standard Error; Standard Errors smaller than the line thickness of the columns are not shown.

\subsection{Proline}

Proline accumulation increased in leaves from November to April (Figure 3). The tuber proline content was relatively low. Elevated values of proline content were detected in petals; in fact, the highest value of proline content was detected in petals from October to November, which were approximately 3-fold higher than those of tubers, leaves and peduncles. Regarding the seasonal values of proline accumulation, significant differences were found among the studied tissues (not shown here). 


\section{Proline Cyclamen graecum}

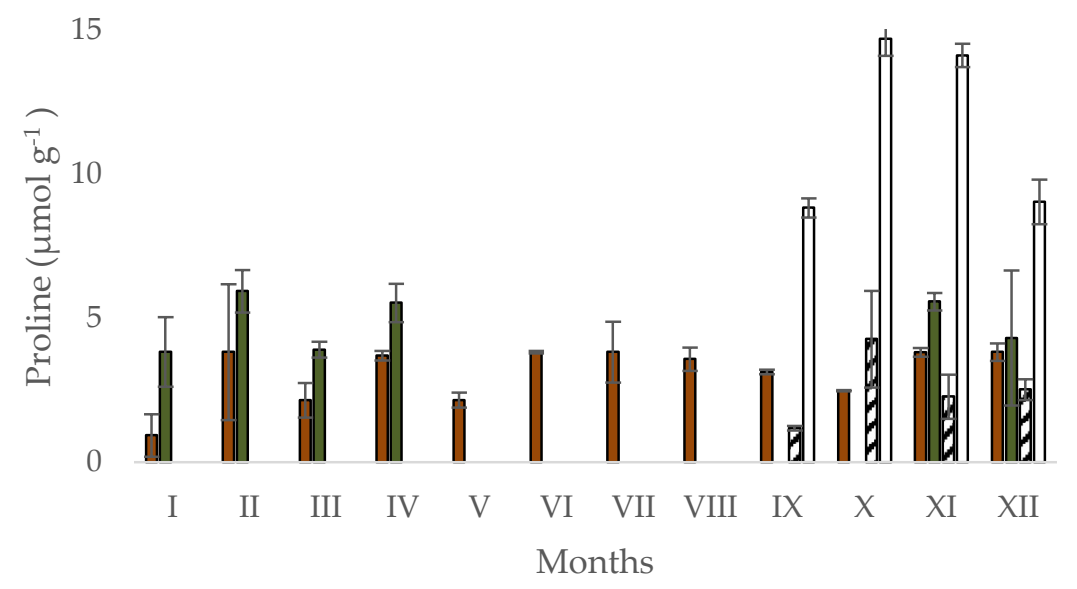

Figure 3. Proline content in tubers (brown bars), leaves (green bars), peduncles (dashed bars) and petals (white bars) of Cyclamen graecum, from January (I) to December (XII). Each column denotes means of five replicates \pm Standard Error; Standard Errors smaller than the line thickness of the columns are not shown.

\section{Discussion}

It is well known that geophytes store substances, usually in the below ground tissues in order to cope with the unfavorable, climatic period of the year. In non-cultivated, wild species, allocation strategies reflect trade-offs between survivorship risk and subsequent fitness benefits, being therefore crucial aspects to a species' ecophysiology. Generally, the geophyte life-cycle and growth strategy are associated with temporal separation of the vegetative and the flowering phases.

Starch is mainly stored in tubers and leaves of Cyclamen graecum and the elevated values from March to April coincide with elevated photosynthetic rates [16]. In tubers elevated accumulation of total sugars was estimated. The underground storage organ reserves are constantly being allocated to other plant parts, such as foliar and floral tissues; starch is the carbon source most likely used exclusively for sprouting of leaves and inflorescences.

The maintenance of petal expansion, during a 4-month season (autumn and winter), seems to be ameliorated by adjustment via osmotic agents, such as proline and soluble sugars, translocated through other plant tissues $[17,18]$. It has been argued that reproductive organs are developed and constructed from resources either recently acquired, or previously stored by the vegetative parts $[19,20]$. In fact, elevated accumulation of soluble sugars and proline in petals (from September to December) may result to a reduction of their osmotic potential, which is expected to maintain their turgor and avoid the harmful effect of declinind temperature $[17,18]$. Additionally, the pronounced proline accumulation in expanded leaves of C. graecum from November to April indicates the protective role of proline in leaves exposed to ambient environmental conditions [21,22].

Author Contributions: J.P. and S.R. conceived and designed the experiments; J.P. performed the experiments; J,P. analyzed the data; J.P. and S.R. wrote the paper. All authors have read and agreed to the published version of the manuscript.

Acknowledgments: The authors would like to thank colleagues of the Botany Depertment for help during this work.

Conflicts of Interest: The authors declare no conflict of interest.

\section{References}

1. Dafni, A.; Cohen, D.; Noy-Mier, I. Life-cycle variation in geophytes. Ann. Mo. Bot. Gard. 1981, 68, 652-660.

2. Negbi, M. Theophrastus on geophytes. Bot. J. Linn. Soc. 1989, 100, 15-43. 
3. Akita, Y.; Ishizaka, H.; Nakayama, M.; Shimada, A.; Kitamura, S., Hase, Y.; Narumi, I.; Tanaka, A. Comparative analysis of floral pigmentation between wild-type and white-flowered varieties of Cyclamen graecum. J. Hortic. Sci. Biotechnol. 2010, 85, 437-443.

4. Scarborough, J. Theophrastus on herbals and herbal remedies. J. Hist. Biol. 1978, 11, 353-385.

5. Gledhill, D. The Names of Plants. Cambridge University Press: Cambridge, UK, 2008; p.130.

6. Grey-Wilson, C. The genus Cyclamen. Christopher Helm Publishers Ltd.: London, UK, 1988.

7. Hughes, N.M.; Carpenter, K.L.; Keidel, T.S.; Miller, C.N.; Waters, M.N.; Smith, W.K. Photosynthetic costs and benefits of abaxial versus adaxial anthocyanins in Colocasia esculenta 'Mojito'. Planta 2014, 240, 971-981.

8. La Rocca, N.; Pupillo, P.; Puppi, G.; Rascio, N. Erythronium dens-canis L. (Liliaceae): An unusual case of change of leaf mottling. Plant Physiol. Biochem. 2014, 74, 108-117.

9. Konoplyova, A.; Petropoulou, Y.; Yiotis, C.; Psaras, G.K.; Manetas, Y. The fine structure and photosynthetic cost of structural leaf variegation. Flora-Morphol. Distrib. Funct. Ecol. Plants 2008, 203, 653-662.

10. Mazouz, W.; Djeddi, S. A biological overview on the Genus Cyclamen. Eur. J. Sci. Res. 2013, 110, 7-22.

11. Dubois, M.; Gilles, K.A.; Hamilton, J.K.; Rebers, P.A.; Smith, F. Colorimetric method for determination of sugars and related substances. Anal. Chem. 1956, 28, 350-356.

12. Buysse, J.; Merckx, R. An improved colorimetric method to quantify sugar content of plant tissue. J. Exp. Bot. 1993, 4, 1627-1629.

13. Meletiou-Christou, M.S.; Rhizopoulou, S. Leaf functional traits of four evergreen species growing in Mediterranean environmental conditions. Acta Physiol. Plant. 2017, 39, 34, doi:10.1007/s11738-016-2330-4.

14. Bates, L.S.; Waldren, R.P.; Teare, I.D. Rapid determination of free proline for water studies. Plant Soil 1973, 39, 205-207.

15. Ain-Lhout, F.; Zunzunegui, M.; Barradas, M.D.; Tirado, R.; Clavijo, A.; Novo, F.G. Comparison of proline accumulation in two Mediterranean shrubs subjected to natural and experimental water deficit. Plant Soil 2001, 230, 175-183.

16. Gratani, L.; Varone, L.; Crescente, M.F. Photosynthetic activity and water use efficiency of dune species: The influence of air temperature on functioning. Photosynthetica 2009, 47, 575-585.

17. Sánchez, F.J.; Manzanares, M.; de Andres, E.F.; Tenorio, J.L.; Ayerbe, L. Turgor maintenance, osmotic adjustment and soluble sugar and proline accumulation in 49 pea cultivars in response to water stress. Field Crop. Res. 1998, 59, 225-235.

18. Rhizopoulou, S.; Diamantoglou, S.T.; Passiakou, L. Free proline accumulation in leaves, stems and roots of four Mediterranean native phrygana species. Acta Oecologica 1990, 11, 585-593.

19. Mooney, H.A.; Winner, W.E.; Pett, E.J. Response of Plants to Multiple Stresses, 2nd ed.; Academic Press: Cambridge, MA, USA, 1991; pp. 161-188.

20. Lundgren, M.R.; Des Marais, D.L. Life history variation as a model for understanding trade-offs in plantenvironment interactions. Curr. Biol. 2020, 30, R180-R189.

21. Rhizopoulou, S.; Meletiou-Christou, M.S.; Diamantoglou, S. Water relations for sun and shade leaves of four Mediterranean evergreen sclerophylls. J. Exp. Bot. 1991, 42, 627-635.

22. Pouris, J.; Meletiou-Christou, M.S.; Chimona, C.; Rhizopoulou, S. Seasonal functional partitioning of carbohydrates and proline among plant parts of the sand saffodil. Agronomy 2020, 10, 539, doi:10.3390/agronomy10040539.

Publisher's Note: MDPI stays neutral with regard to jurisdictional claims in published maps and institutional affiliations.

(C) 2020 by the authors; licensee MDPI, Basel, Switzerland. This article is an open access article distributed under the terms and conditions of the Creative Commons by Attribution (CC-BY) license (http://creativecommons.org/licenses/by/4.0/). 